\begin{tabular}{|c|c|}
\hline 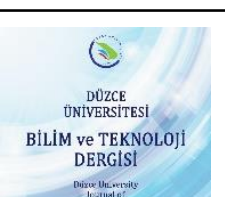 & $\begin{array}{l}\text { Düzce Üniversitesi } \\
\text { Bilim ve Teknoloji Dergisi }\end{array}$ \\
\hline$\therefore \because$ & \\
\hline
\end{tabular}

\title{
Sı ̆̆ Kriyojenik İşlemin Sarıçam (Pinus sylvestris L.) Odunu Eğilme Direnci ve Elastikiyet Modülü Üzerine Etkilerinin Araştırılması
}

\author{
Hasan Hüseyin CIRITCIOĞLU, ${ }^{a}$, \\ a Ăgaçişleri Endüstri Mühendisliği Bölümü, Teknoloji Fakültesi, Düzce Üniversitesi, Düzce, TÜRKIYYE \\ ${ }^{b}$ Inönü Mesleki ve Teknik Anadolu Lisesi, Mobilya ve İç Mekan Tasarımı Alanı, İstanbul/TÜRKIYE. \\ * Sorumlu yazarin e-posta adresi: hasanciritcioglu@duzce.edu.tr
}

DOI: $10.29130 /$ dubited.670380

\begin{abstract}
ÖZET
Bu çalışmada farklı rutubet miktarına (RM) sahip (HK-Hava kurusu, LD- Lif doygunluğu ve SD- Suya doymuş) Sarıçam (Pinus sylvestris L.) odununa $-70^{\circ} \mathrm{C}$ 'de sı̆̆ kriyojenik işlem (SKİ) uygulamanın ağaç malzemenin eğilme direnci ve elastikiyet modülü özelliklerindeki etkileri araştırılmıştır. Eğilme direncinin (ED) belirlenmesinde TS 2474, eğilmede elastikiyet modülünün (EEM) belirlenmesinde ise TS 2478 esaslarına uyulmuştur. SKI uygulanması ile örneklerin ED ve EEM üzerinde kayda değer artışlar gözlenmiştir. Ayrıca SKİ uygulamanın ED ve EEM üzerindeki etkisi istatistiksel olarak anlamlı bulunmuştur $(p \leq 0,05)$. Malzemelerin maruz kaldıkları RM arttıkça ED ve EEM değerlerinin düştüğü görülmüştür. RM'nin ED üzerindeki etkisi istatistiksel olarak anlamlı iken $(p \leq 0,05)$, EEM üzerindeki etkisi anlamsız bulunmuştur. Çalışma sonucu en yüksek ED $\left(101,16 \mathrm{~N} / \mathrm{mm}^{2}\right)$ - $70{ }^{\circ} \mathrm{C}$ SKİ uygulanmış HK rutubetindeki örneklerde görülürken en düşük ED $\left(76,05 \mathrm{~N} / \mathrm{mm}^{2}\right)$ SKİ uygulanmamış SD örneklerde görülmüştür. Benzer şekilde en yüksek EEM $\left(12629,2 \mathrm{~N} / \mathrm{mm}^{2}\right)$ SKİ uygulanmış HK rutubet miktarlı örneklere görülürken en düşük EEM $\left(8759 \mathrm{~N} / \mathrm{mm}^{2}\right)$ SKİ uygulanmamış LD rutubet miktarına sahip örneklerde görülmüştür. Sonuç olarak SKİ uygulamanın ağaç malzemenin mekanik özellikleri üzerinde olumlu etkiye sahip olduğu söylenebilir.
\end{abstract}

Anahtar Kelimeler: Ă̆aç modifikasyonu, Mekanik özellikler, Sarıçam, Sĭ̆ kriyojenik işlem

\section{Investigation of the Effects of Shallow Cryogenic Treatment on Bending Strength and Modulus of Elasticity of Scots Pine (Pinus sylvestris L.)}

\begin{abstract}
In this study, the application of shallow cryogenic treatment (SCT) to the Scotch Pine wood (Pinus sylvestris L.) which has different moisture content (MC type; AD-air dry, FS-fiber saturation and WS-water-saturated) and effects on bending strength and modulus of elasticity properties were investigated. TS 2474 principles were used for determination of bending strength (BS) and TS 2478 principles were used for determination of modulus of elasticity (MOE). Significant increases in the BS and MOE of the samples were observed with the application of SCT. In addition, the effect of SCT on BS and MOE was found to be statistically significant $(p \leq 0.05)$. It was observed that BS and MOE values decreased due to the increase in MC to which the materials were exposed. The effect of MC on BS was statistically significant $(p \leq 0.05)$ and there was no statistically significant difference for MOE. As a result of the study, the highest BS $\left(101,16 \mathrm{~N} / \mathrm{mm}^{2}\right)$ was observed in AD moisture content samples with $-70{ }^{\circ} \mathrm{C} \mathrm{SCT}$, while the lowest BS $\left(76,05 \mathrm{~N} / \mathrm{mm}^{2}\right)$ was observed in WS moisture content samples without SCT.
\end{abstract}

Geliş: 04/01/2020, Düzeltme: 15/08/2020, Kabul: 20/08/2020 
Similarly, the highest MOE $\left(12629,2 \mathrm{~N} / \mathrm{mm}^{2}\right)$ was observed in AD moisture content samples with $-70{ }^{\circ} \mathrm{C} \mathrm{SCT}$, while the lowest MOE $\left(8759 \mathrm{~N} / \mathrm{mm}^{2}\right)$ was observed in FS moisture content samples without SCT. As a result, it could be said that SCT application has a positive effect on the mechanical properties of wood material.

Keywords: Wood modification, Mechanical properties, Scotch Pine, Shallow cryogenic treatment

\section{GIRISS}

Ağaç malzemenin kullanım yerlerindeki ömrü ve performansının belirlenmesi için malzemenin mekanik özelliklerinin bilinmesi gerekmektedir. Ağaç malzemenin en belirleyici mekanik özellikleri arasında ED (eğilme direnci) ve EEM (eğilmede elastikiyet modülü) yer almaktadır. Ağaç malzemenin mekanik özellikleri genel olarak, ağacın yoğunluğu, yıllık halka düzeni gibi yapısal özelliklerin yanı sıra ahşabın nem içeriği ve sıcaklığın karmaşık bir etkileşimine bağlıdır [1-3].

Ağaç malzemenin neredeyse tüm mekanik özellikleri üzerinde rutubet miktarı ve sıcaklığın doğrudan etkisi vardır. Ağaç malzemenin mekanik özellikleri özellikle lif doygunluğu (LD) rutubet miktarının (yaklaşık \%30) altına düştükçe ve sıcaklık azaldıkça artış göstermektedir [4]. Ağaç malzeme rutubeti LD rutubet miktarının üzerinde olması durumunda mekanik özelliklerinde göz ardı edilebilir düzeyde değişiklikler yaşanmaktadır, ayrıca çok düşük RM olması durumunda ahşabın bazı mekanik özellikleri elde edilen en yüksek dayanım değerlerine ulaşılmasının ardından tekrar düşmeye başlamaktadır $[5,6]$. Benzer etkileşimler ahşap esaslı kompozit malzemelerde de gözlenmektedir. Örneğin; Ayrılmiş ve ark. yaptıkları çalışmada $-30{ }^{\circ} \mathrm{C}$ ile $+30^{\circ} \mathrm{C}$ arasında değişen sıcaklıklara maruz bırakılan ahşap esaslı kompozit malzemelerde $0{ }^{\circ} \mathrm{C}$ den $-30^{\circ} \mathrm{C}$ 'ye sıcaklığın düşürülmesi ile ED \%9,8 EEM \%7,4 artarken sıcaklığın $0{ }^{\circ} \mathrm{C}$ den $+30{ }^{\circ} \mathrm{C}$ 'ye artırılması ile ED \%12,5 ve EEM \% 9,6 azaldığını ifade etmiştir [7]. Benzer şekilde ekstrem sıcaklık koşullarında $\left(-173{ }^{\circ} \mathrm{C}\right)$ Huş ağacından üretilen kontrplak örnekleri üzerinde yapılan testler, malzemenin rutubet miktarı ve kriyojenik sıcaklık koşullarının gerilme/gerinim ilişkileri üzerinde büyük etkiye sahip olduğunu göstermektedir $[8,9]$ ve bu etkiler malzemenin mekanik özelliklerindeki değişimi açıklamaktadır.

Rutubet miktarı ve sıcaklık değişimine bağlı olarak ağaç malzemenin mekanik özelliklerinde ortaya çıkan değişimi ele alan çok sayıda çalışma bulunmaktadır. Bu çalışmalarda sıcaklık düşüşüne bağlı olarak ahşabın mekanik özelliklerinde artış yaşandığı $[4,10,11]$ vurgulanmakla beraber ahşabın rutubet miktarının mekanik dayanım üzerindeki etkisinin LD rutubet miktarının altında özellikle önemli olduğu ve LD rutubetin üzerindeki rutubet miktarlarında sıcaklık $0{ }^{\circ} \mathrm{C}$ 'nin altına düştügünde etkilediğini ortaya koymaktadır $[2,4,12,13]$. Örneğin; Gerhard (1982), rutubet miktarı LD rutubetin üzerinde olduğunda ED ve EEM'nin $-50{ }^{\circ} \mathrm{C}$ de $20^{\circ} \mathrm{C}$ 'ye göre sirasiyla $\% 110$ ve $\% 50$ daha yüksek olduğunu bulmuştur [4]. Bir diğer çalışmada ise sıcaklık $20^{\circ} \mathrm{C}$ 'den $-30{ }^{\circ} \mathrm{C}$ 'ye düştügünde $\mathrm{ED}$ ve EEM rutubet miktarı $\% 50$ olduğunda sırasıyla $\% 130$ ve $\% 86$ daha yüksek olduğunu, rutubet miktarı $\% 210$ olduğunda ise ED'nin \% 485, EEM'nin ise \%220 daha yüksek olduğu belirtilmektedir [14]. Bu çalışmaların ortak yanı, $0{ }^{\circ} \mathrm{C}$ 'nin altındaki düşük sıcaklıklarda ağaç malzemelere muamele edilerek aynı sıcaklık koşullarında mekanik testlerin yapılmış olmasıdır. Bu nedenle ağaç malzeme içerisindeki su donmakta ve hücre boşlukları buz kristalleri ile dolmaktadır. Ağaç malzeme içerisindeki serbest su ve higroskopik suyun donması ve genleşmesi ile selüloz moleküllerinin hareketinin daha zorlaştığı, sonuç olarak esnekliğin azaldığı söylenebilir [15-17].

$\mathrm{Bu}$ çalışmada farklı rutubet miktarlarındaki ağaç malzemeler SKİ uygulaması akabinde mekanik testler yapılmak üzere tekrar HK rutubet miktarına iklimlendirildikleri için yukarıda bahsedilen literatürden farklıdır. Literatürde kriyojenik sıcaklıklara maruz kalan ağaç malzemenin tekrar normal koşullarda HK rutubet miktarına döndürüldükten sonra mekanik özelliklerini belirlemeye yönelik herhangi bir çalışmaya rastlanılmamıştır. 
Bilindiği üzere kriyojenik işlem özellikle metal malzemelerin mekanik özelliklerini (aşınma dayanımı, sertlik, çekme dayanımı, gerilim giderme ve kırılma tokluğu vb.) iyileştirmek amacıyla kullanılmaktadır $[18,19]$. Kriyojenik işlem uygulama sıcaklığına göre $-50{ }^{\circ} \mathrm{C}$ ile $-100{ }^{\circ} \mathrm{C}$ arasında sığ ve $-125^{\circ} \mathrm{C}$ 'den daha düşük sıcaklıklarda ise derin kriyojenik işlem olarak adlandırılmaktadır [19]. Kendra ve Cortez 2010 yılında Amerika Birleşik Devletlerinde aldıkları patentte, ahşap beysbol sopalarına kriyojenik işlem uygulanması ile beyzbol sopalarının mekanik özelliklerinin iyileştirildiğini vurgulamaktadır [20]. Bu çalışmada ahşap bir beyzbol sopasının $-190{ }^{\circ} \mathrm{C}$ 'de 24 saat boyunca kriyojenik işlem ile muamele edildikten sonra ED'nin \%26 arttı̆̆ını ortaya koymaktadır. Ayrıca bu çalışmada kriyojenik işleme maruz bırakılmış ahşap beysbol sopalarının vuruş esnasındaki titreşim etkisinin iyileştiği ve kırılmalarda ortaya çıkan sivri uçlu parçalarında büyük oranda azaldığg belirtilmektedir [20].

$\mathrm{Bu}$ çalışma, alınan bu patente belirtilen ağaç malzemenin kriyojenik işleme maruz bırakılması ile mekanik özelliklerinin iyileştirilebildiği iddiasından hareketle, ağaç malzeme mekanik özelliklerinin iyileştirilmesi amacıyla kriyojenik muamelenin bir modifikasyon aracı olarak kullanılabilirliğini araştırmak amacı ile yapılmıştır. Bu doğrultuda endüstride yaygın kullanım alanı olan yerli ibreli türlerimizden Sarıçam (Pinus sylvestris L.) odunları 3 farklı rutubet miktarına (HK, LD, SD) kondisyonlanmış ve $-70{ }^{\circ} \mathrm{C}$ 'de (SKI) 2 saat süre ile maruz bırakılmıştır. Akabinde örneklerin ED ve EEM değerlerindeki değişimler çok faktörlü varyans analizleri ile istatistiksel olarak analiz edilmiştir.

\section{MATERYAL VE METOT}

\section{A. METERYAL}

\section{A. 1. Ağaç Malzeme ve Örneklerin Hazırlanması}

Çalışmada endüstride sıç̧a kullanılan ibreli türlerden Sarıçam (Pinus sylvestris L.) keresteleri kullanılmıştır. Keresteler TS 2470'de belirtilen ilkelere uygun olacak şekilde İstanbul Keresteciler sitesinden rastgele örnekleme yöntemiyle seçilmiştir [21]. Seçilen kerestelerin; budaksız, çatlaksız, renk değişimi, mantar ve böcek tahribatı olmayan, öz odunu içermeyen ve düzgün lif yapısına sahip olmasına özen gösterilmiştir.

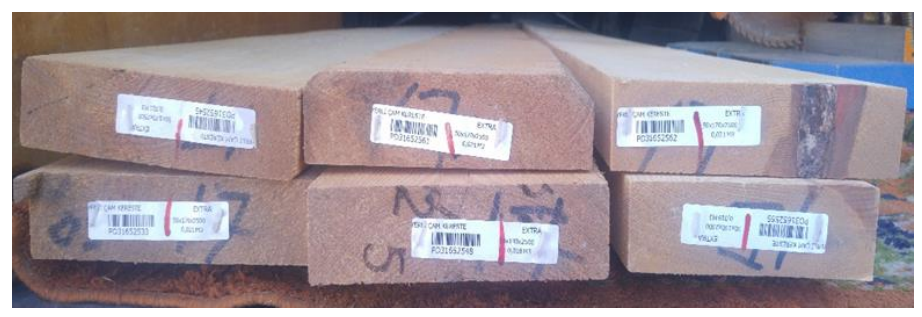

Şekil 1. Deneylerde kullanılan Sarıçam kerestelere ait en kesit görünümü

\section{A. 2. Kriyojenik İşlem Sistemi}

Hazırlanan deney örneklerine kriyojenik işlem uygulanmasında Alper ısıl işlem firmasında bulunan bilgisayar kontrollü dolaylı soğutma yapılan kriyojenik işlem sistemi kullanılmıştır. Kullanılan sistemde soğutma için kullanılan sıvı azot kabin içerisine girdiğinde gaz fazına dönüşmekte ve kriyojenik işlem uygulanacak parçalar ile teması engellenmektedir. Sistemde kullanılan bilgisayar otomasyonu aracıllı̆ 1 ile kabin içerisinde oda sıcaklığından arzu edilen sıcaklık değerlerine ortalama $2{ }^{\circ} \mathrm{C} / \mathrm{dk}$ hızla tedrici olarak ulaşılmaktadır. Arzu edilen kriyojenik sıcaklıkta bekletme süresinin sonunda, aynı şekilde ortam sıcaklığı tedrici olarak oda sıcaklığına yükseltilerek kriyojenik işlem uygulaması tamamlanmaktadır. 


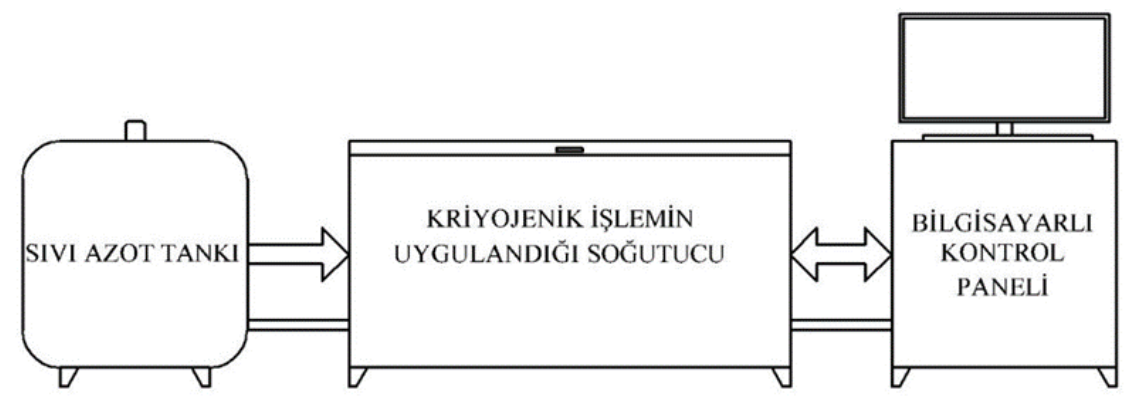

Şekil 2. Doğrudan soğutma prensibi ile çalışan sıfır altı işlem sistemi şematik gösterimi

\section{B. METOT}

Uygulanan sığ kriyojenik işlem-SKİ $\left(-70^{\circ} \mathrm{C}\right)$ ve farklı rutubet miktarlarının-RM (HK-Hava Kurusu, LDLif Doygunluğu, SD-Suya Doymuş) Sarıçam odunu eğilme direnci ve elastikiyet modülü üzerindeki etkilerini belirlemek üzere deney numuneleri 3 gruba ayrılarak kondisyonlanmıştır. HK rutubet (\%12) için deney numuneleri $20 \pm 2{ }^{\circ} \mathrm{C}$ sıcaklıkta ve bağıl nemi $\% 65 \pm 3$ olan iklimlendirme kabininde, LD rutubet için $17{ }^{\circ} \mathrm{C}$ sıcaklıkta ve bağıl nemi \%95 olan iklimlendirme kabininde değişmez ağırlığa ulaşıncaya kadar bekletilmiştir. SD rutubet içeriği elde etmek için örnekler distile su ile doldurulmuş plastik bir hazne içerisinde değişmez ağırlığa gelinceye kadar su altında bekletilmiştir. Deney örneklerinin farklı rutubet miktarlarına getirilme süreçleri Şekil 3’te görülmektedir.
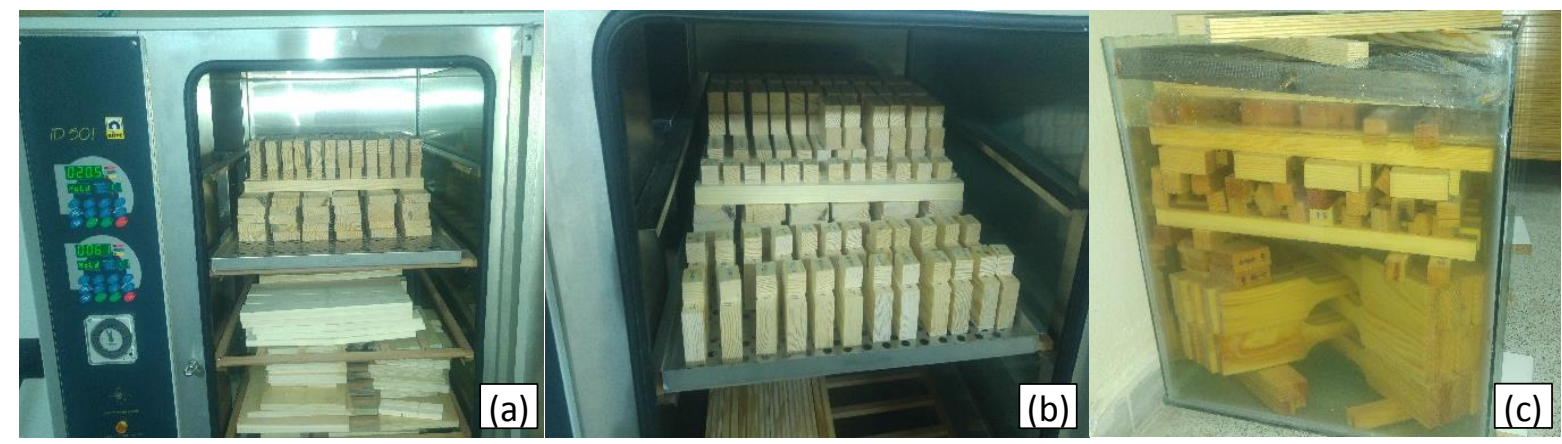

Şekil 3. (a) HK rutubet için örneklerin hazırlanması, (b) LD rutubet için örneklerin hazırlanması, (c) SD rutubet için örneklerin hazırlanması

Farklı rutubet miktarlarına kondisyonlanmış deney örnekleri rutubet miktarında değişim yaşanmaması için vakumlu plastik ambalajlara yerleştirilerek ambalaj içerisindeki hava vakumlanmıştır. Hazırlanan deney örnekleri zaman kaybetmeden kriyojenik işlem görmek üzere firmaya nakledilmiştir. Deney örnekleri kriyojenik işlem tankı içerisine yerleştirilerek öncelikle ortam sıcaklığından $-70{ }^{\circ} \mathrm{C}$ sıcaklığa ulaşılmış ve bu sıcaklıkta 2 saat bekletilmiştir. SKİ sonrasında örneklerde tamamen donma sağlandığı gözlenmiştir.

SKİ uygulamasının akabinde tekrar ortam sıcaklığına ulaşılana kadar tedrici olarak sıcaklık artırılmak suretiyle kriyojenik işlem süreci tamamlanmıştır. Kriyojenik işlem sonrası deney örnekleri $20 \pm 2{ }^{\circ} \mathrm{C}$ sıcaklıkta ve bağıl nemi \%65 $\% 3$ olan iklimlendirme kabininde değişmez ağırlığa gelene kadar tekrar kondisyonlanmıştır. Bu işlem ile eğilme direnci ve elastikiyet modülünü belirlemek üzere yapılacak deneyler için tüm örneklerin HK denge rutubetine ( \% 12) gelmesi sağlanmıştır. Deney örnekleri nihai olarak HK denge rutubetine getirilmiş olsalar dahi, örneklerinin daha önce farklı rutubet miktarına denge rutubetine getirilmesi ve SKİ uygulanması sonucu yaşanabilecek olası boyutsal değişimlerin deney sonuçları üzerindeki olası etkilerini göz önünde bulundurmak amaciyla tüm örneklerin deneyler öncesi tekrar ölçümleri alınarak deneyler gerçekleştirilmiştir. 


\section{B. 1. Eğilme Direnci ve Eğilmede Elastikiyet Modülü}

Çalışma kapsamında farklı rutubet miktarına sahip ve sığ kriyojenik işleme $\left(-70{ }^{\circ} \mathrm{C}\right)$ maruz kalmış deney örneklerinin eğilme dirençlerinin (ED) belirlenmesinde TS 2474, eğilmede elastikiyet modülünün (EEM) belirlenmesinde ise TS 2478 esaslarına uyularak deneyler gerçekleştirilmiştir. Deney numune örneği, düzeneğin şematik gösterimi ve uygulama görüntüsü Şekil 4’te görülmektedir.

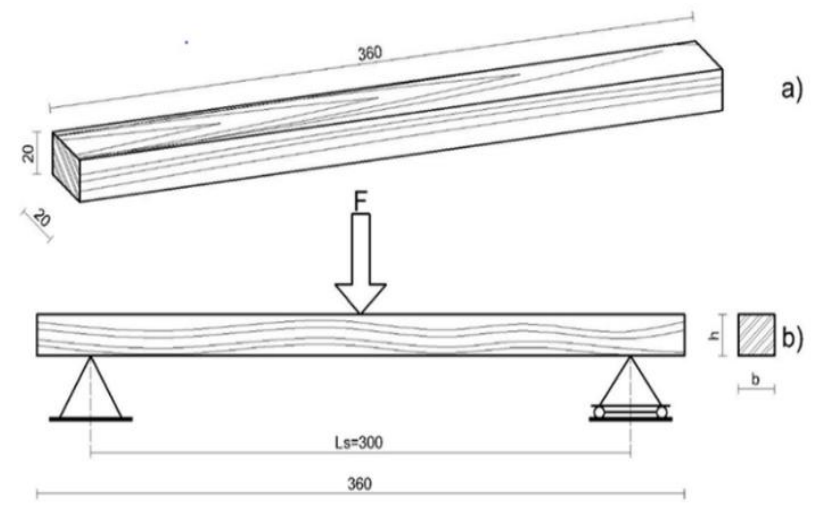

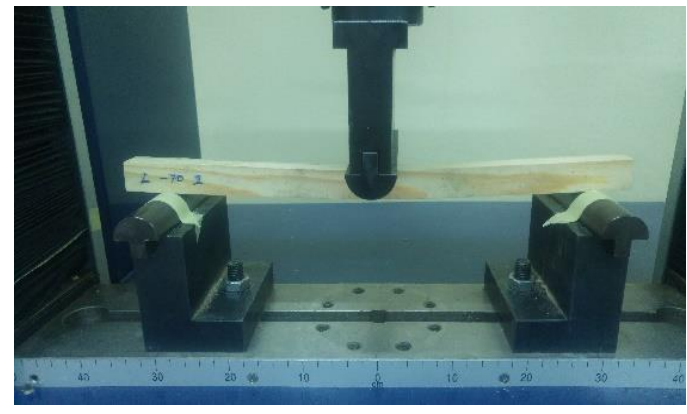

c)

Şekil 4. Liflere dik ED ve EEM (a) deney numune örneği, (b) deney şematik gösterimi (ölçüler mm 'dir), (c) deney uygulama görüntüsü.

Deney numuneleri, ilgili standartta belirtildiği üzere 360 × 20 × $20 \mathrm{~mm}$ ölçülerinde her bir grup için beşer adet hazırlanmıştır. Eğilme direnci ve eğilmede elastikiyet modülünün belirlenmesi için U-TEST marka $50 \mathrm{kN}$ yükleme kapasiteli üniversal test cihazı kullanılmıştır. Standartta belirtildiği üzere, deneylerin 1,5 $\pm 0,5$ dakika içerisinde tamamlanması için yükleme hızı ayarlanarak sabit tutulmuş ve testlerin bu süre içerisinde tamamlanması sağlanmıştır.

Deney numunelerinin eğilme dirençleri Eşt. 1 kullanılarak hesaplanmıştır.

$$
\sigma_{e}=\frac{3 \cdot F_{\max } \cdot L_{s}}{2 \cdot a \cdot b^{2}}
$$

Burada; $\sigma_{e}$ : Eğilme direnci $\left(\mathrm{N} / \mathrm{mm}^{2}\right) F_{\max }$ : Kırılma anındaki maksimum kuvvet $(\mathrm{N}), L_{s}$ : Destek noktaları arası açıklık (mm), $a$ : Deney örneği genişliği $(\mathrm{mm})$ ve $b$ : Deney örneği kalınlığını $(\mathrm{mm})$ ifade etmektedir. Eğilmede elastikiyet modülü ise Eşt. 2 kullanılarak hesaplanmıştır.

$$
E m=\frac{\Delta F \cdot L_{s}^{3}}{4 \cdot b \cdot h^{3} \cdot \Delta f}
$$

Burada; $E_{m}$ : Elastikiyet modülü $\left(\mathrm{N} / \mathrm{mm}^{2}\right), \Delta F$ : Elastikiyet bölgesindeki kuvvet fark1 $(\mathrm{N}), L_{s}$ : Destek noktaları arası açıklık (mm), $a$ : Deney örneği genişliği $(\mathrm{mm})$ ve $b$ : Deney örneği kalınlığını $(\mathrm{mm})$ ve $\Delta f$ : Eğilme miktarını (mm) ifade etmektedir.

\section{B. 2. Bulguların İstatistik Analizi}

Yapılan istatistik analizlerle, farklı rutubet miktarlarında kondisyonlanmış ve SKİ uygulanmış deney örnekleri ile kontrol gurubu (SKİ uygulanmamış) örnekleri arasında ED ve EEM açısından anlamlı fark olup olmadığının belirlenmesi amaçlanmıştır. Uygulanacak istatistik yöntemin belirlenmesi amaciyla öncelikle deneyler sonucu elde edilen verilere normalite testleri uygulanarak dağılım özellikleri belirlenmiştir. Akabinde gruplar arası farkın önem kontrolü için kurulan hipotezleri test etmek amacıyla, 
iki grup arası farkın önem kontrolü için $T$ testi ve ikiden fazla olan gruplar için çok faktörlü varyans analizleri uygulanmıştır. Son olarak, gruplar arası farkın önemli bulunduğu gruplarda hangi grup ortalamasının diğerlerinden farklı olduğunu belirlemek üzere çoklu karşıllaştırma (post-hoc) testlerinden Duncan çoklu genişlik testi uygulanmıştır.

\section{BULGULAR VE TARTISSMA}

Sarıçam (Pinus sylvestris L.) odunlarından hazırlanan 3 farklı rutubet miktarında kondisyonlanmış sı̆̆ kriyojenik işlem uygulanmış ve uygulanmamış deney örnekleri (kontrol grupları) üzerinde gerçekleştirilen eğilme direnci ve elastikiyet modülü test sonuçları Tablo 1'de verilmiştir.

Tablo 1. Eğilme direnci ve eğilmede elastikiyet modülü aritmetik ortalama ve standart sapmalart

\begin{tabular}{ccccccccc}
\hline $\begin{array}{c}\text { Rutubet } \\
\text { Seviyesi }\end{array}$ & $\begin{array}{c}\text { ED } \\
\left(\mathrm{N} / \mathrm{mm}^{2}\right)\end{array}$ & $\begin{array}{c}\text { Standart } \\
\text { Sapma }\end{array}$ & $\begin{array}{c}\text { EEM } \\
\left(\mathrm{N} / \mathrm{mm}^{2}\right)\end{array}$ & $\begin{array}{c}\text { Standart } \\
\text { Sapma }\end{array}$ & $\begin{array}{c}\text { ED } \\
\left(\mathrm{N} / \mathrm{mm}^{2}\right)\end{array}$ & $\begin{array}{c}\text { Standart } \\
\text { Sapma }\end{array}$ & $\begin{array}{c}\text { EEM } \\
\left(\mathrm{N} / \mathrm{mm}^{2}\right)\end{array}$ & $\begin{array}{c}\text { Standart } \\
\text { Sapma }\end{array}$ \\
\hline HK & 85,68 & 7,40 & 10550,60 & 2069,98 & 101,16 & 3,28 & 12629,20 & 440,89 \\
\hline LD & 89,29 & 4,97 & 8759,00 & 1289,33 & 91,72 & 16,01 & 11259,80 & 2887,41 \\
\hline SD & 76,05 & 3,13 & 8903,00 & 1004,11 & 80,72 & 9,46 & 10609,60 & 1471,34 \\
\hline
\end{tabular}

Uygulanan normalite testi sonucu her iki veri setinin de normal dağılım gösterdiği görülmüştür $(\boldsymbol{p}>\mathbf{0 , 0 5})$. Gruplar arası farkın önem kontrolü için parametrik testlerden iki grup ortalamalarının karşılaştırılmasında T-testi ikiden fazla grup için ise çok faktörlü varyans analizi uygulanmasına karar verilmiştir.

\section{A. EĞIILME DİRENCİ}

Ağaç malzemenin mekanik özellikleri türe özgü niteliklerin yanı sıra çevresel faktörlerden de etkilenmektedir. Ağaç malzemedeki rutubet miktarı ve maruz kaldığı sıcaklığa göre fiziksel ve mekanik özellikleri önemli oranda etkilenmektedir [4-22]. Bu nedenle çalışma kapsamında uygulanan 3 farklı rutubet miktarı (RM) ve sı̆̆ kriyojenik işlemin (SKİ) eğilme direnci üzerindeki etkilerini belirlemek amacıyla çok faktörlü varyans analizi uygulanmıştır.

Çok faktörlü varyans analizi sonuçları Tablo 2'de görülmektedir. Tablo 2'den görüldügüü üzere ağaç malzemenin eğilme direnci üzerinde rutubet miktarı ve uygulanan sı̆̆ kriyojenik işlemin istatistiksel olarak anlamlı etkisi olduğu $(\mathrm{p} \leq 0,05)$ bulunmuştur. RM ve SKI'nin ikili etkileşimleri ise $\% 95$ güven düzeyinde istatistiksel olarak anlamlı bulunmamıştır.

Tablo 2. Liflere dik eğilme direnci çok faktörlü varyans analizi

\begin{tabular}{lccccc}
\hline Faktör & $\begin{array}{c}\text { Kareler } \\
\text { Toplamı }\end{array}$ & $\begin{array}{c}\text { Serbestlik } \\
\text { Derecesi }\end{array}$ & $\begin{array}{c}\text { Kareler } \\
\text { Ortalaması }\end{array}$ & F & p $\leq \mathbf{0 , 0 5}$ \\
\hline RM & 1272,37 & 2 & 636,19 & 8,55 & $\mathbf{0 , 0 0 2}$ \\
\hline SKİ & 424,66 & 1 & 424,66 & 5,71 & $\mathbf{0 , 0 2 5}$ \\
\hline RM*SKİ & 243,63 & 2 & 121,82 & 1,64 & 0,215 \\
\hline Hata & 1785,11 & 24 & 74,38 & & \\
\hline Toplam & 3725,77 & 29 & & & \\
\hline *:\%95 güven düzeyinde anlamlı & & & &
\end{tabular}

Eğilme direnci üzerindeki etkisi anlamlı bulunan RM faktöründe hangi grup ortalamasının diğerlerinden farklı olduğunu belirlemek üzere çoklu karşılaştırma testlerinden (post-hoc) Duncan çoklu genişlik testi uygulanmıştır. Tablo 3'de Duncan testi sonucu RM'ye göre eğilme direnci homojenlik grupları (HG) görülmektedir. 
Tablo 3. RM'ye göre eğilme direnci homojenlik gruplarl $\left(\mathrm{N} / \mathrm{mm}^{2}\right)$

\begin{tabular}{ccc}
\hline $\begin{array}{c}\text { Örneklerin } \\
\text { Rutubet Miktarı } \\
(\text { RM) }\end{array}$ & \multicolumn{2}{c}{ Homojenlik Grupları (HG) } \\
\cline { 2 - 3 } HK & $\mathbf{A}$ & $\mathbf{B}$ \\
\hline LD & $\mathbf{9 3 , 4 2 4}$ \\
\hline SD & $\mathbf{9 0 , 5 0 2}$ \\
\hline
\end{tabular}

RM'ye göre eğilme dirençlerinin iki farklı HG'de toplandığı görülmektedir. En yüksek eğilme direnci HK rutubet miktarına sahip örneklerde $93,424 \mathrm{~N} / \mathrm{mm}^{2}$ iken en düşük eğilme direnci $78,382 \mathrm{~N} / \mathrm{mm}^{2}$ olarak SD rutubet miktarına sahip örneklerde görülmüştür. SD rutubet miktarına sahip deney örneklerinin eğilme dirençleri LD rutubet miktarına sahip örneklerden yaklaşık \%15, HK rutubet miktarına sahip örneklerden ise yaklaşı \% 19 daha düşük eğilme direncine sahip olduğu görülmektedir. $\mathrm{Bu}$ durum ağaç malzemenin maruz kaldığı rutubet miktarı arttıkça malzemenin eğilme direncinin olumsuz etkilendiğini ortaya koymaktadır.

SKİ uygulama işleminin ağaç malzeme mekanik özelliklerinden ED ve EEM üzerindeki etkisini belirlemek amacıyla farklı rutubet miktarlarına (HK, LD ve SD) kondisyonlanmış kontrol grupları oluşturulmuş ve aynı RM'ye sahip diğer örnek gruplarına SKİ uygulanmıştır. HK rutubette SKİ uygulanması ile örneklerin eğilme dirençlerinde ortaya çıkan değişim ele alındığında, SKİ uygulanmayan örneklerin ortalama eğilme direnci $85,68 \mathrm{~N} / \mathrm{mm}^{2}$ iken $-70{ }^{\circ} \mathrm{C}$ de SKİ uygulanan örneklerin ortalama eğilme direnci $101,16 \mathrm{~N} / \mathrm{mm}^{2}$ olarak belirlenmiştir (Tablo 1). Tablo 4'ten görüldüğü üzere farklı RM'ye sahip örneklerde SKİ uygulama durumuna göre yapılan karşılaştırmada, HK RM'na sahip örnekler için iki örnek varyansları Levene testi sonucuna göre türdeş olduğu için $(\mathrm{F}=1,249, \mathrm{P}=0,296), \mathrm{T}$ testi sonuçlarından eşit varyans varsayımı $\mathrm{t}$ testi sonuçları kullanılmıştır. $\mathrm{LD}$ ve SD RM'na sahip örneklerde ise iki örnek varyansları Levene testi sonucuna göre türdeş olmadığı için (sırasıyla $\mathrm{F}=4,175, \mathrm{P}=0,075$ ve $\mathrm{F}=7,060$ ve $\mathrm{P}=0,029$ ) $\mathrm{T}$ testi sonuçlarından farklı varyans varsayımı $\mathrm{T}$ testi sonuçları kullanılmıştır. HK RM'na sahip örneklerin SKİ uygulanması sonucu ED değerlerinde ortaya çıkan bu fark Tablo 4'ten görüldüğü üzere $\% 95$ güven düzeyinde istatistiksel olarak anlamlı $(p \leq 0,05)$ bulunmuştur. SKİ uygulaması ile Sarıçam örneklerin eğilme dirençlerinde yaklaşık \%18 oranında artış olduğu görülmektedir. LD ve SD rutubetteki numunelerin eğilme dirençlerinde de artış gözlemlenmiş olsa da bu artış istatistiksel olarak anlamlı $(p \geq 0,05)$ düzeyde değildir (Tablo 4$)$.

Tablo 4. Farklı RM uygulanmış örneklerin SKİ uygulama durumuna göre ED, T testi sonuçları

\begin{tabular}{|c|c|c|c|c|c|c|}
\hline & & $\mathbf{F}$ & Sig. (P) & $\mathbf{t}$ & SD & $p \leq 0,05^{*}$ \\
\hline \multirow{2}{*}{ HK } & $\begin{array}{c}\text { Eşit varyans } \\
\text { varsayımı }\end{array}$ & \multirow{2}{*}{1,249} & \multirow{2}{*}{0,296} & $-4,272$ & 8 & 0,003 \\
\hline & $\begin{array}{c}\text { Farklı varyans } \\
\text { varsayımı }\end{array}$ & & & $-4,272$ & 5,517 & 0,006 \\
\hline \multirow{2}{*}{ LD } & $\begin{array}{c}\text { Eşit varyans } \\
\text { varsayımı }\end{array}$ & \multirow{2}{*}{4,175} & \multirow{2}{*}{0,075} & $-0,324$ & 8 & 0,755 \\
\hline & $\begin{array}{c}\text { Farkl1 varyans } \\
\text { varsayımı }\end{array}$ & & & $-0,324$ & 4,766 & $\mathbf{0 , 7 6 0}$ \\
\hline \multirow{2}{*}{ SD } & $\begin{array}{c}\text { Eşit varyans } \\
\text { varsayımı }\end{array}$ & \multirow{2}{*}{7,060} & \multirow{2}{*}{0,029} & $-1,046$ & 8 & 0,326 \\
\hline & $\begin{array}{l}\text { Farkl1 varyans } \\
\text { varsayım }\end{array}$ & & & $-1,046$ & 4,868 & 0,345 \\
\hline
\end{tabular}

Literatürde ağaç malzemenin rutubet miktarındaki artışa bağlı olarak eğilme direnci ve diğer mekanik özelliklerin olumsuz etkilendiğini açıklayan çok sayıda çalışma bulunmaktadır. Örneğin, Gerhard (1982), ahşabın rutubet miktarının LD rutubet miktarının altına düştükçe neredeyse tüm mekanik 
özelliklerde artış olduğunu ifade etmektedir [4]. LD rutubetin üzerindeki rutubet miktarlarında ise ahşabın mekanik özelliklerinde ihmal edilebilir düzeyde değişim ortaya çıkmaktadır [5].

$\mathrm{Bu}$ çalışmada deney örnekleri kriyojenik işlem öncesi farklı rutubet miktarlarına kondisyonlanmış ve kriyojenik işlem sonrasında tüm örnekler $20{ }^{\circ} \mathrm{C}$ sıcaklıkta $\% 65 \pm 3$ bağıl nemi olan iklimlendirme dolabında yaklaşık \%12 denge rutubet miktarına gelecek şekilde tekrar kondisyonlanmış ve mekanik testler bu koşullarda gerçekleştirilmiştir. Dolayısı ile tüm örnekler aynı rutubet ve sıcaklık koşullarında deneye tabi tutulduklarından ED'leri arasında istatistiksel olarak anlamlı bir fark çıması beklenilmemektedir. Fakat yapılan çalışma sonucu Tablo 3 'ten görüldüğü üzere başlangıç rutubet miktarı HK ve LD olan örnekler aynı homojenlik grubunda yer alırken SD örnekler çok daha düşük ED değeri ile farklı homojenlik grubunda yer almıştır. Ayrıca Tablo 1'den görüldügüü üzere HK rutubet miktarına sahip örneklerde SKİ uygulaması ile ED'nin yaklaşık \%19, LD rutubet miktarına sahip örneklerde yaklaşık \% 3 ve SD rutubet miktarına sahip örneklerde yaklaşık \% 6 oranında artış gösterdiği görülmektedir. Bu durum uygulanan SKİ uygulamasının ağaç malzemenin ED üzerinde olumlu etkiye sahip olduğunu göstermektedir. Bu durum Tablo 4 'ten görüldüğü üzere yapılan farklı rutubet miktarları için ayrı ayrı gerçekleştirilen T-testi ile doğrulanmaktadır. Ortaya çıkan bu etkinin istatistiksel olarak anlamlılığını belirlemek üzere başlangıç rutubetlerinden bağımsız olarak SKİ uygulanmış ve uygulanmamış örneklerin ED değerleri bağımsız iki gurup arası farkın önem kontrolü için $T$ testi ile karşılaştırılmıştır. T testi sonucu Tablo 5 'te görülmektedir.

Tablo 5. SKİ uygulama durumuna göre ED, T testi sonucu

\begin{tabular}{lccccc}
\hline & F & Sig. $(\mathbf{P})$ & t & SD & $\boldsymbol{p} \leq \mathbf{0 , 0 5}^{*}$ \\
\hline $\begin{array}{c}\text { Eșit varyans } \\
\text { varsayım1 }\end{array}$ & 6,891 & $\mathbf{0 , 0 1 4}$ & $-1,898$ & 28 & 0,068 \\
\hline $\begin{array}{c}\text { Farkl1 varyans } \\
\text { varsayım1 }\end{array}$ & & & $-1,898$ & 22,413 & $\mathbf{0 , 0 7 1}$ \\
\hline
\end{tabular}

Burada amaç Tablo 4'ten görüldügü üzere yalnızca HK rutubete sahip örneklerde görülen istatistiksel olarak anlamlı bulunan farkın yanı sıra diğer RM'na kondisyonlanmış örneklerde SKİ uygulama ile görülen ve istatistiksel olarak anlamlı bulunmayan artışların birlikte değerlendirilmesi sonucu SKİ uygulamasının RM'den bağımsız olarak etkisinin belirlenmesidir. Tablo 5 'ten görüldüğü üzere SKİ uygulama durumuna göre yapılan karşılaştırmada, iki örnek varyansları Levene testi sonucuna göre türdeş olmadığı için $(\mathrm{F}=6,891, \mathrm{P}=0,014)$, $\mathrm{T}$ testi sonuçlarından farklı varyans varsayımı $\mathrm{T}$ testi sonuçları kullanılmıştır. Yapılan T testi sonucuna göre iki grup ortalamaları arasındaki farkın istatistiksel olarak anlamlı olmadığı görülmüştür ( $\mathrm{p} \geq 0,05)$. Bu doğrultuda her ne kadar SKİ ile örneklerin ED değerlerinde artış gözlense de tüm başlangıç rutubetleri birlikte göz önünde bulundurulduğunda bu artışın istatistiksel olarak anlamlı olmadığı görülmüştür. Bu durumun, ağaç malzemenin başlangıçta maruz bırakıldığı farklı rutubet miktarları nedeniyle ortaya çıan yapısal değişimlerden kaynaklandığı söylenebilir.

\section{B. EĞIILMEDE ELASTIKIIYET MODÜLÜ}

Eğilmede elastikiyet modülü (EEM) ağaç malzemenin elastiklik özelliklerini belirten ve kullanım yerlerindeki performansını gösteren önemli mekanik özelliklerden birisidir. EEM, eğilme direncine benzer şekilde ağaç malzemenin yapısal özelliklerinin yanı sıra rutubet içeriği ve maruz kalınan sıcaklığa bağlı olarak değişiklik göstermektedir [1,2].

Uygulanan testler sonucunda en yüksek EEM değeri HK rutubette SKİ uygulanan numunelerde $\left(12629 \mathrm{~N} / \mathrm{mm}^{2}\right)$, en düşük değer ise LD rutubetteki kriyojenik işlem uygulanmamış numunelerde $\left(8759 \mathrm{~N} / \mathrm{mm}^{2}\right)$ görülmüsstür (Tablo 1$)$.

Çalışma kapsamında SKİ'nin farklı rutubet miktarlarındaki ağaç malzemelerin EEM üzerine etkisini belirlemek amacıyla çok faktörlü varyans analizi uygulanmıştır ve sonuçları Tablo 6' da verilmiştir. 
Tablo 6. Eğilmede elastikiyet modülü çok faktörlü varyans analizi

\begin{tabular}{lrcrrr}
\hline \multicolumn{1}{c}{ Faktör } & $\begin{array}{c}\text { Kareler } \\
\text { Toplamı }\end{array}$ & $\begin{array}{c}\text { Serbestlik } \\
\text { Derecesi }\end{array}$ & $\begin{array}{c}\text { Kareler } \\
\text { Ortalaması }\end{array}$ & F & \multicolumn{1}{c}{$\boldsymbol{p} \leq \mathbf{0 , 0 5}$} \\
\hline RM & 19747096,07 & 2 & 9873548,03 & 3,36 & 0,052 \\
\hline SKİ & 32928163,33 & 1 & 32928163,33 & 11,19 & $\mathbf{0 , 0 0 3}$ \\
\hline RM*SKİ & 789492,07 & 2 & 394746,03 & 0,13 & 0,875 \\
\hline Hata & 70607490,00 & 24 & 2941978,75 & & \\
\hline Toplam & 124072241,50 & 29 & & & \\
*:\%95 güven düzeyinde anlamlı & & & &
\end{tabular}

Tablo 6'dan görüldüğü üzere SKI'nin eğilmede elastikiyet modülü üzerinde istatistiksel olarak anlamlı $(\boldsymbol{p} \leq \mathbf{0 , 0 5})$ etkisi bulunmaktadır. RM ve RM-SKI ikili etkileşimlerinin ise anlamlı bir etkisi gözlemlenmemiştir.

Uygulanan SKI'nin ağaç malzeme EEM üzerindeki etkisi incelendiğinde Tablo 1'den görüldüğü üzere en yüksek EEM 12629,2 N/mm² ile hava kurusu rutubet miktarında SKİ uygulanan numunelerde elde edilmiştir. En düşük EEM ise $8759 \mathrm{~N} / \mathrm{mm}^{2}$ ile LD RM'na sahip kontrol grubu numunelerinde elde edilmiştir. Farklı RM'ye sahip kontrol grupları ile SKİ uygulanmış örnek grupları karşılaştırıldığında HK ve SD RM'ye sahip örneklerde EEM'nin yaklaş1k \%19, LD RM'ye sahip örneklerde ise yaklaşık \%28 artış olduğu görülmektedir. ED sonuçlarına benzer şekilde ağaç malzemenin EEM özelliğinin de SKİ uygulaması ile iyileştirilebildiği sonucuna varılmaktadır.

Ortaya çıkan bu etkinin istatistiksel olarak anlamlılı̆̆ını belirlemek üzere farklı rutubet miktarlarına kondisyonlanmış kontrol grubu örnekleri ile SKİ uygulanmış örneklerin EEM ortalamaları arasındaki farkın önem kontrolü için T-testi uygulanmış ve elde edilen sonuçlar Tablo 7'de sunulmuştur.

Tablo 7. Farklı RM uygulanmış örneklerin SKİ uygulama durumuna göre EEM, T testi sonuçları

\begin{tabular}{|c|c|c|c|c|c|c|}
\hline & & $\mathbf{F}$ & Sig. (P) & $\mathbf{t}$ & SD & $p \leq 0,05^{*}$ \\
\hline \multirow{2}{*}{ HK } & $\begin{array}{l}\text { Eşit varyans } \\
\text { varsayımı }\end{array}$ & \multirow{2}{*}{41,322} & \multirow{2}{*}{0,00} & $-2,196$ & 8 & 0,059 \\
\hline & $\begin{array}{c}\text { Farklı varyans } \\
\text { varsayımı }\end{array}$ & & & $-2,196$ & 4,362 & $\mathbf{0 , 0 8 7}$ \\
\hline \multirow{2}{*}{ LD } & $\begin{array}{c}\text { Eşit varyans } \\
\text { varsayımı }\end{array}$ & \multirow{2}{*}{4,333} & \multirow{2}{*}{0,071} & $-1,768$ & 8 & 0,115 \\
\hline & $\begin{array}{c}\text { Farkl1 varyans } \\
\text { varsayımı }\end{array}$ & & & $-1,768$ & 5,534 & 0,132 \\
\hline \multirow{2}{*}{ SD } & $\begin{array}{c}\text { Eşit varyans } \\
\text { varsayımı }\end{array}$ & \multirow{2}{*}{0,260} & \multirow{2}{*}{0,624} & $-2,142$ & 8 & 0,065 \\
\hline & $\begin{array}{c}\text { Farklı varyans } \\
\text { varsayımı }\end{array}$ & & & $-2,142$ & 7,062 & 0,069 \\
\hline
\end{tabular}

Tablo 7'den görüldüğü üzere HK RM'na sahip örneklerde iki örnek varyansları Levene testi sonucuna göre $(\mathrm{F}=41,322, \mathrm{P}=0,00)$ türdeş olmadığ için farklı varyans varsayımı kullanılmıştır. LD ve SD RM'na sahip örneklerde ise iki örnek varyansları Levene testi sonucuna göre (sırasıyla $F=4,333, P=0,071$ ve $\mathrm{F}=0,260$ ve $\mathrm{P}=0,624)$ varyansları türdeş olduğundan $\mathrm{T}$ testi sonuçlarından eşit varyans varsayımı $\mathrm{t}$ testi sonuçları kullanılmıştır. Tablodan görüldüğü üzere tüm RM için kontrol grupları ile SKİ uygulanmış örnek grupları arasında iki grup ortalamaları arasındaki farkın $\% 95$ güven düzeyin istatistiksel olarak anlamlı olmadığ1 $(p \geq 0,05)$ görülmüştür.

Başlangıç rutubetlerinden bağımsız olarak SKİ uygulanmış ve uygulanmamış örneklerin EEM değerleri bağımsız iki gurup arası farkın önem kontrolü için $T$ testi ile karşılaştırılmıştır. Burada amaç farklı RM'ye kondisyonlanmış kontrol grubu örnekleri ile SKİ uygulanmış örnek grubu EEM değeri ortalamaları arasındaki farkın bütünsel olarak değerlendirilmek sureti ile SKİ uygulaması ile EEM 
değerlerinde istatistiksel olarak anlamlı farkın ortaya çıkıp çıkmadığının değerlendirilmesidir. $\mathrm{Bu}$ doğrultuda gerçekleştirilen bağımsız iki örnek T testi sonucu Tablo 8'de görülmektedir.

Tablo 8. SKI uygulama durumuna göre EEM, T testi sonucu

\begin{tabular}{lccccc}
\hline & F & Sig. (P) & t & SD & $\boldsymbol{p} \leq \mathbf{0 , 0 5}$ \\
\hline $\begin{array}{c}\text { Eșit varyans } \\
\text { varsayım1 }\end{array}$ & 1,062 & $\mathbf{0 , 3 1 2}$ & $-3,181$ & 28 & $\mathbf{0 , 0 0 4}$ \\
\hline $\begin{array}{c}\text { Farkl1 varyans } \\
\text { varsayım1 }\end{array}$ & & & $-3,181$ & 27,195 & 0,004 \\
\hline
\end{tabular}

Tablo 8'den görüldüğü üzere SKİ uygulama durumuna göre yapılan karşılaştırmada, iki örnek varyansları Levene testi sonucuna göre varyanslar türdeş olduğu için $(\mathrm{F}=1,062, \mathrm{P}=0,312), \mathrm{T}$ testi sonuçlarından eşit varyans $t$ testi sonuçları kullanılmıştır. Yapılan $T$ testi sonucuna göre iki grup ortalamaları arasındaki farkın istatistiksel olarak anlamlı olduğu görülmüştür $(\mathrm{p} \leq 0,05)$. Bu doğrultuda SKİ uygulaması ile RM faktörü dikkate alınmaksızın örneklerin EEM değerlerinde istatistiksel olarak anlamlı bir artış sağlandığı ve SKİ uygulaması ile ağaç malzemenin EEM değerinde kayda değer bir iyileşme sağlanabildiği söylenebilir. Elde edilen bu sonuç Tablo 6'dan da görüldügü üzere çok faktörlü varyans analizi sonucu ile tutarlıdır.

Sonuç olarak SKİ uygulaması ile kriyojenik işlem uygulanmış beysbol sopalarına ilişkin alınan patente belirtilen iyileştirmelere benzer şekilde ağaç malzemenin mekanik özelliklerinin SKİ uygulaması ile iyileştirilebildiği kanaatine varılmıştır.

\section{IV.SONUC}

Sonuç olarak ağaç malzemenin mekanik özelliklerinden ED üzerinde RM ve SKİ'nin istatistiksel olarak anlaml etkiye sahip olduğu belirlenmiştir $(\boldsymbol{p} \leq \mathbf{0 , 0 5})$. RM*SKİ ikili etkileşimlerinin ise ED üzerindeki etkisi istatistiksel olarak anlamsız bulunmuştur. SKİ uygulamasının EEM üzerindeki etkisi istatistiksel olarak anlamlı iken RM ve RM*SKİ ikili etkileşimlerinin EEM üzerindeki etkisi istatistiksel olarak anlamsız bulunmuştur $(\boldsymbol{p} \geq \mathbf{0 , 0 5})$. SKİ uygulamasının ED üzerinde HK rutubet miktarındaki örneklerde yaklaşık \%18, LD rutubetindeki örneklerde $\% 3$ ve SD rutubetindeki örneklerde \%6 oranında artış sağladığ 1 görülmüştür. Benzer şekilde $\mathrm{EEM}$ değerleri HK ve SD rutubetindeki örneklerde yaklaşı \% 19, LD rutubetindeki örneklerde yaklaşı \%28 oranında iyileştirme sağladığı belirlenmiştir.

Uygulanan başlangıç rutubetlerinden bağımsız olarak SKİ uygulama ile sağlanan iyileştirmelerin istatistiksel olarak anlamlılığ 1 karşılaştırıldığında ED için istatistiksel olarak anlamlı fark bulunmazken EEM değerleri için bu farkın istatistiksel olarak anlamlı olduğu görülmüştür. Elde edilen bulgular ağaç malzemenin yüksek rutubet içeriğine maruz bırakılması sonucu, her ne kadar tekrar $\% 12$ rutubet miktarı koşuluna döndürülseler de maruz kalınan yüksek rutubet içeriğinin malzemenin mekanik özellikleri üzerinde kalıcı deformasyonlara yol açabildiğini göstermektedir. Özellikle SD rutubet miktarını elde edebilmek üzere ağaç malzemenin su altında bekletilmesi sonucu malzemede yapısal bozulmalar meydana geldiği kanaati oluşmuştur. SKİ uygulaması ile bu etkiler bir miktar giderilebilse de HK ve LD rutubet miktarına maruz kalan örnekler kadar iyi sonuçlar elde edilememiştir.

Sonuç olarak SKİ uygulaması işlem maliyetleri göz önünde bulundurulmak şartıyla ağaç malzemenin mekanik özelliklerinin iyileştirilmesi için bir modifikasyon yöntemi olarak kullanılabilir olduğu söylenebilir. İleri çalışmalarda daha düşük sıcaklıklar, işlem süresi ve ağaç malzemenin işlenmesine yönelik diğer faaliyetlere olan etkilerin de araştırılması önerilmektedir. 


\section{CIKARIM}

Kriyojenik işlemin metallerde olduğu gibi ağaç malzemenin mekanik özelliklerinin iyileştirilmesi için bir modifikasyon yöntemi olarak kullanılabilir olduğu düşünülmektedir.

\section{KAYNAKLAR}

[1] L.C. Palka, "Predicting the effect of specific gravity, moisture content, temperature and strain rate on the elastic properties of softwoods," Wood Science and Technology, vol. 7, no. 2, pp. 127-141, 1973.

[2] R.E. Hernández, L. Passarini, A. Koubaa, "Effects of temperature and moisture content on selected wood mechanical properties involved in the chipping process," Wood Science and Technology, vol. 48, n. 6, pp. 1281-1301, 2014.

[3] S.V. Glass, S.L. Zelinka, "Moisture Relations and Physical Properties of Wood" in Centennial Edition Wood Handbook - Wood as an Engineering Material General Technical Report FPL: GTR-190, Madison, WI: US Dept. of Agriculture, Forest Service, Forest Products Laboratory, 2010, ch. 4, pp. 4.14.19 .

[4] C.C. Gerhards, "Effect of moisture content and temperature on the mechanical properties of wood: an analysis of immediate effects," Wood and Fiber, vol. 14, n. 4, pp. 36, 1982.

[5] M. Arnold, "Effect of moisture on the bending properties of thermally modified beech and spruce," Journal of Materials Science, vol. 45, pp. 669-680, 2010.

[6] B. Richard, "Drying and Control of Moisture Content and Dimensional Changes" in Centennial Edition Wood Handbook - Wood as an Engineering Material General Technical Report FPL: GTR-190, Madison, WI: US Dept. of Agriculture, Forest Service, Forest Products Laboratory, 2010, ch. 13, pp. 13.1-13.20.

[7] N. Ayrilmis, Ü. Buyuksari ve N. As, "Bending strength and modulus of elasticity of wood-based panels at cold and moderate temperatures," Cold Regions Science and Technology, vol. 63 n. 1-2, pp. 40-43, 2010.

[8] L. Caetano, B. Galpin, V. Grolleau and J-D. Capdeville, "Behaviour of a birch plywood under various experimental conditions," EPJ Web of Conferences, vol. 94, p. 05010, 2015.

[9] L. Caetano, V. Grolleau, B. Galpin, A. Penin and J.D. Capdeville, "High strain rate out-of-plane compression of birch plywood from ambient to cryogenic temperatures," Strain, vol. 54, n.2, pp. 117, 2018.

[10] D.W. Green, J.W. Evans, J.D. Logan and W.J. Nelson, "Adjusting Modulus of Elasticity of Lumber for Changes in Temperature," Forest Product Journal, vol. 49, pp. 82-94, 1999.

[11] A. Mishiro, "Effect of freezing treatments on the bending properties of wood," Bulletin of the Tokyo University Forests, vol. 82, pp. 177-189, 1990.

[12] S. Gao, X. Wang and L. Wang, "Modeling temperature effect on dynamic modulus of elasticity of red pine (Pinus resinosa) in frozen and non-frozen states," Holzforschung, vol. 69, pp. 233-240, 2015.

[13] L. Zhao, J. Lu, Y. Zhou and J. Jiang, "Effect of low temperature cyclic treatments on modulus of elasticity of birch wood," BioResources, vol. 10, n. 2, pp. 2318-2327, 2015. 
[14] A. Mishiro and I. Asano, "Mechanical properties of wood at low temperatures: Effect of moisture content and temperature of the bending properties of wood, 2: Moisture content beyond the fiber-saturation point," Mokuzai Gakkaishi-Journal of the Japan Wood Research Society, vol. 30, pp. 277-286, 1984.

[15] L. Zhao, J. Jiang, J. Lu and T. Zhan, "Flexural property of wood in low temperature environment," Cold Regions Science and Technology, vol. 116, pp. 65-69, 2015.

[16] R. A. Schmidt and J.W. Pomeroy, "Bending of a conifer branch at subfreezing temperatures: implications for snow interception," Canadian Journal of Forest Research, vol. 20, pp.1251-1253, 2008.

[17] L. Zhao, J. Jiang and J. Lu, "Effect of thermal expansion at low temperature on mechanical properties of Birch wood," Cold Regions Science and Technology, vol. 126, pp. 61-65, 2016.

[18] J.Y. Huang, Y.T. Zhu, X.Z. Liao, I.J. Beyerlein, M.A. Bourke and T.E. Mitchell, "Microstructure of cryogenic treated M2 tool steel," Materials Science and Engineering A, vol. 339, pp. 241-244, 2003.

[19] A. Akhbarizadeh, A. Shafyei and M.A. Golozar, "Effects of cryogenic treatment on wear behavior of D6 tool steel," Materials and Design, vol. 30, pp. 3259-3264, 2009.

[20] G. D. Kendra and J. Cortez, "Cryogenically treated wooden baseball bat," U.S. Patent 2010/0307170 A1, Dec. 9, 2010.

[21] TSE 2470. Odunda Fiziksel ve Meknaiksel Deneyler için Numune Alma Metotları ve Genel Özellikler. Ankara: Türk Standartları Enstitüsü; 1970.

[22] D. Green and J. Evans, "The Immediate Effect of Temperature on the Modulus of Elasticity of Green and Dry Lumber," Wood and Fiber Science, vol. 40, pp. 374-383, 2008. 